\title{
THE EVALUATION OF THE EOSINOPENIC RESPONSE TO CORTICOTROPHIN AND CORTISONE IN THE NEWBORN INFANT
}

\author{
BY \\ JAMES W. FARQUHAR \\ From the Department of Child Life and Health, University of Edinburgh
}

(RECEIVED FOR PUBUCATION OCTORER 4, 1954)

The eosinopenic response to stress has been recognized since Zappert (1893) described its occurrence in certain infections, and in recent years it has been included among the phenomena of the alarm reaction (Selye, 1949).

It was also shown that a decrease in the number of circulating eosinophils followed the injection of corticotrophin or cortisone, and Hills, Forsham and Finch (1948) concluded that stress induced eosinopenia by the release of these hormones.

Thorn, Forsham, Prunty and Hills (1948) demonstrated that the secretion of the adrenal cortex was essential if eosinopenia were to be produced, and from this devised the Thorn test. Following the determination of the absolute eosinophil count an adult receives $25 \mathrm{mg}$. of corticotrophin and the percentage decrease in four hours is found. Thorn et al. believed that a decrement of $50 \%$ or more should occur in the presence of healthy adrenal cortex.

The significance of the results is dependent upon the stability of the eosinophil count in normal people over a similar time interval, and it has been shown by Swanson, Bauer and Ropes (1952) from a review of the literature and from a small but carefully studied series of their own that spontaneous variations of this magnitude may in fact occur at certain periods of the 24 hours in adults.

The test has been employed also in newborn infants, but no careful study of hourly changes in the absolute eosinophil level at that age can be found. It was decided, therefore, to undertake an evaluation of the test in the neonatal period by determining the nature of the spontaneous variation over a four-hour interval and to note any relationship that might exist between eosinophil change and disturbance of the baby.

The second part of the investigation was planned to determine what responses could be obtained by the injection of varying doses of corticotrophin and cortisone. Finally it was hoped to determine whether the magnitude of the response varied with the age of the infant.

\section{METHODS}

\section{Part I}

Three groups of newborn infants, conforming to the criteria of normality previously employed (Farquhar, 1954), were selected at random. The first- and third-day groups each contained 15 infants and there were 16 in the tenth-day group. Six hours were allowed to elapse before studying infants on the first day in order to avoid the rapid eosinophil changes previously described as occurring in that period.

The first count was carried out at $9.30 \mathrm{a} . \mathrm{m}$. in the majority, but at $10.30 \mathrm{a} . \mathrm{m}$. in a few, and thereafter at intervals of one hour until 3.30 p.m.

The infants were fed at $9.45 \mathrm{a} . \mathrm{m}$. and $1.45 \mathrm{p} . \mathrm{m}$. so that all were fed once in the first four hours, or just before starting in a few, and twice in the six hours.

The infant's reaction to the pain of heel-stabbing was also noted and graded as follows: (1) Cried when stabbed and for some time thereafter; (2) cried when stabbed; (3) restless and whimpered when stabbed; (4) no response.

The technique of eosinophil counting was that described by McArthur, Smart, MacLachlan, Terry, Harting, Gautier, Godly, Swallow, Simeone, Zygmuntowicz, Christo, Crepeaux, Point and Benson (1954), and employed in previous work (Farquhar, 1954).

\section{Part II}

Varying dosages of corticotrophin and cortisone were injected into different groups of normal newborn infants at $9.30 \mathrm{a} . \mathrm{m}$. and the percentage change induced in the eosinophil count was determined.

The infants in some of the groups were given the same dosage of the hormone on the first, third and tenth days, so providing serial studies of response in individuals. Lest the response to a third injection after the interval of a week might be influenced by the infant's having 
received two injections previously, separate groups were given the same dose on days one and three and on days three and ten.

Both the corticotrophin and cortisone were fresh and taken from the same batches. The corticotrophin was later checked favourably against another batch by the same manufacturer and a further batch by another manufacturer. A tuberculin syringe was employed for the injection of cortisone in order to achieve more aocurate dosage.

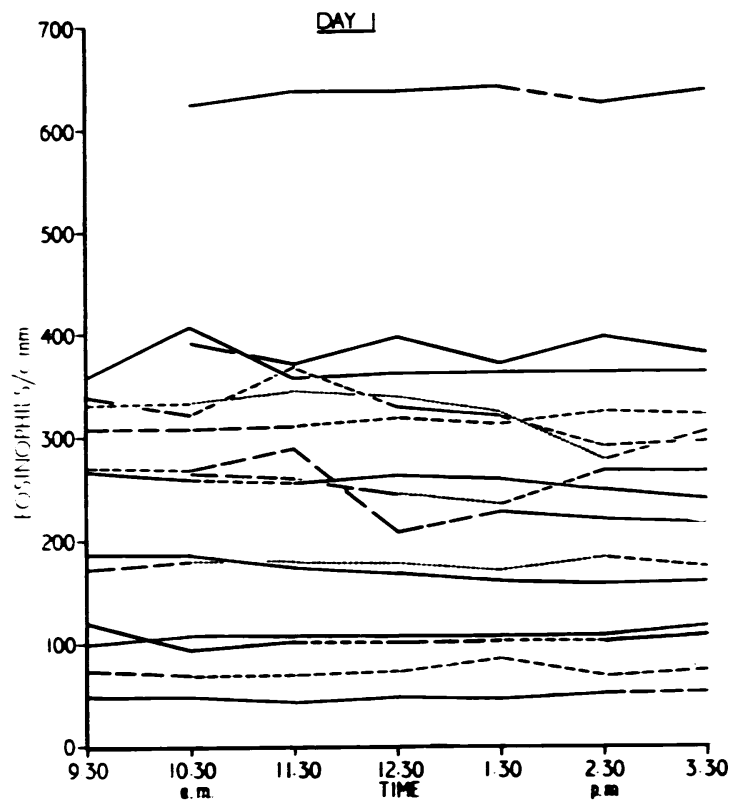

FiG. 1.

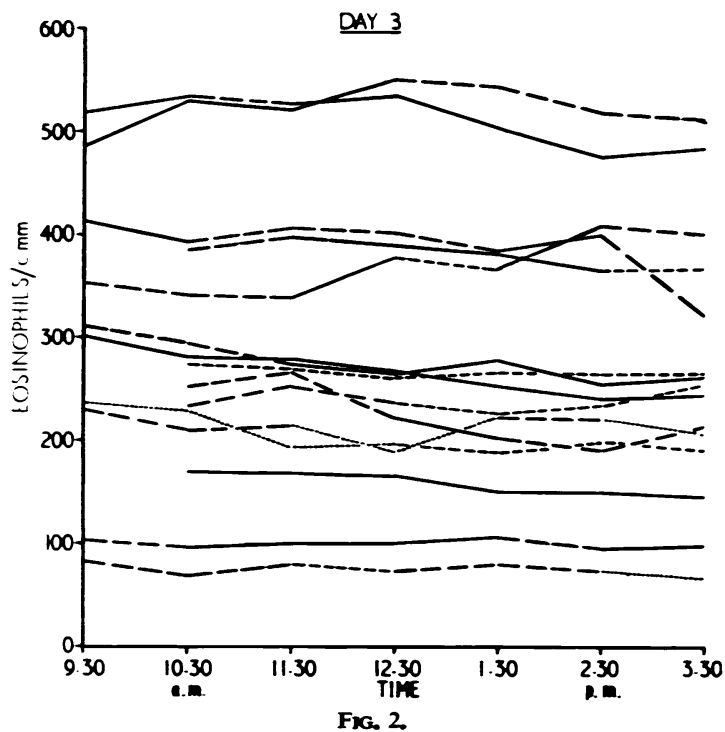

\section{RESULTS}

\section{Part I}

It may be seen (Figs. 1-3) that there was little spontaneous change in the eosinophil counts of individuals during the same six-hour period on the first, third and tenth days of life.

Of the 15 cases studied on the first day there was insignificant hourly variation in 10 , a moderate downward trend in three, a slight downward trend in one and the count fluctuated a little in one. Only six of the 15 infants studied on the third day had very stable eosinophil counts. Four showed a slight and two a moderate downward trend, two a slight upward trend and some fluctuation occurred in one. On the tenth day the count was stable in 11 of the 16 infants, two showed a slight and one a moderate downward trend and in two there was a little fluctuation.

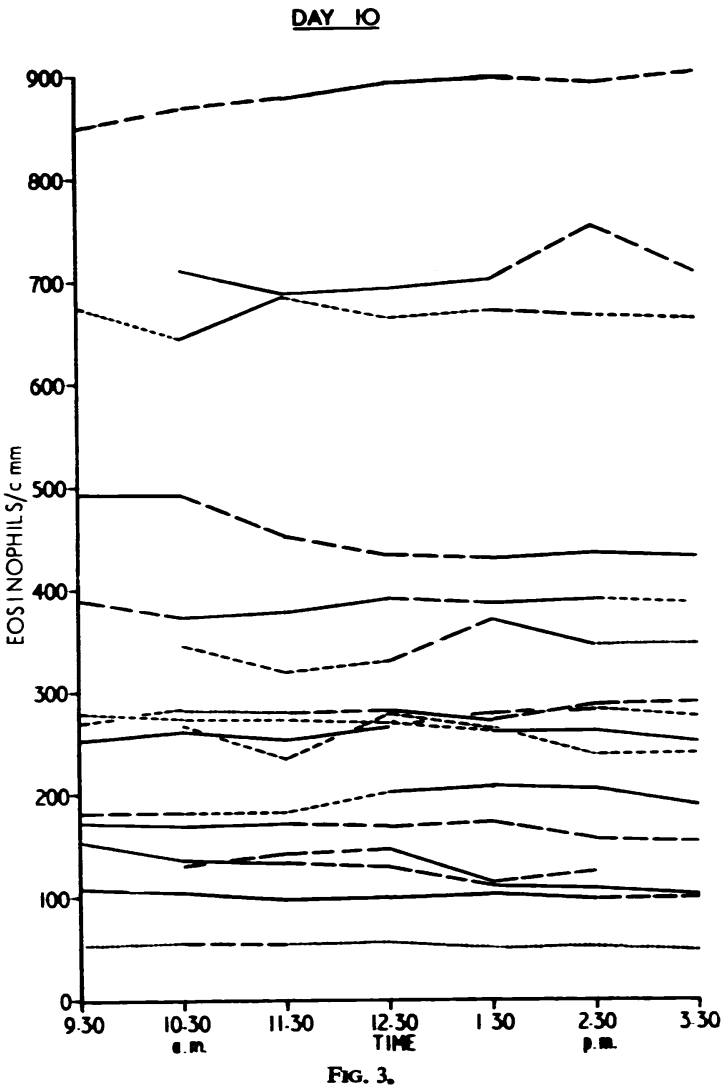

Fucs, 1, 2 and 3.-Hourly observations on the cosinophil counts of normal infants on Days 1,3 and 10.

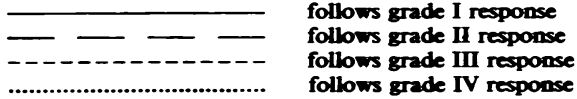




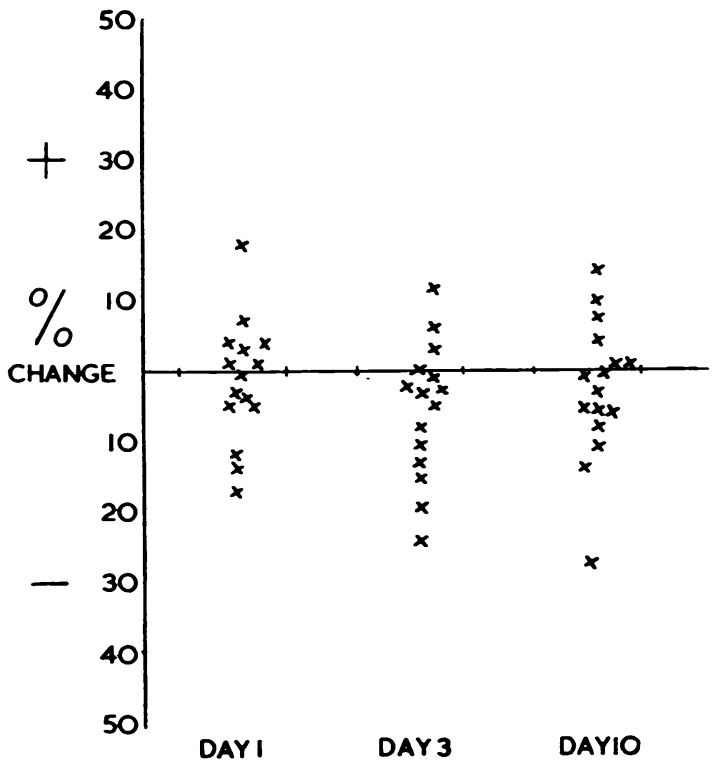

FiG. 4.-Eosinophil levels of newborn infants, showing spontaneous change in four hours on Days 1, 3 and 10 of life.

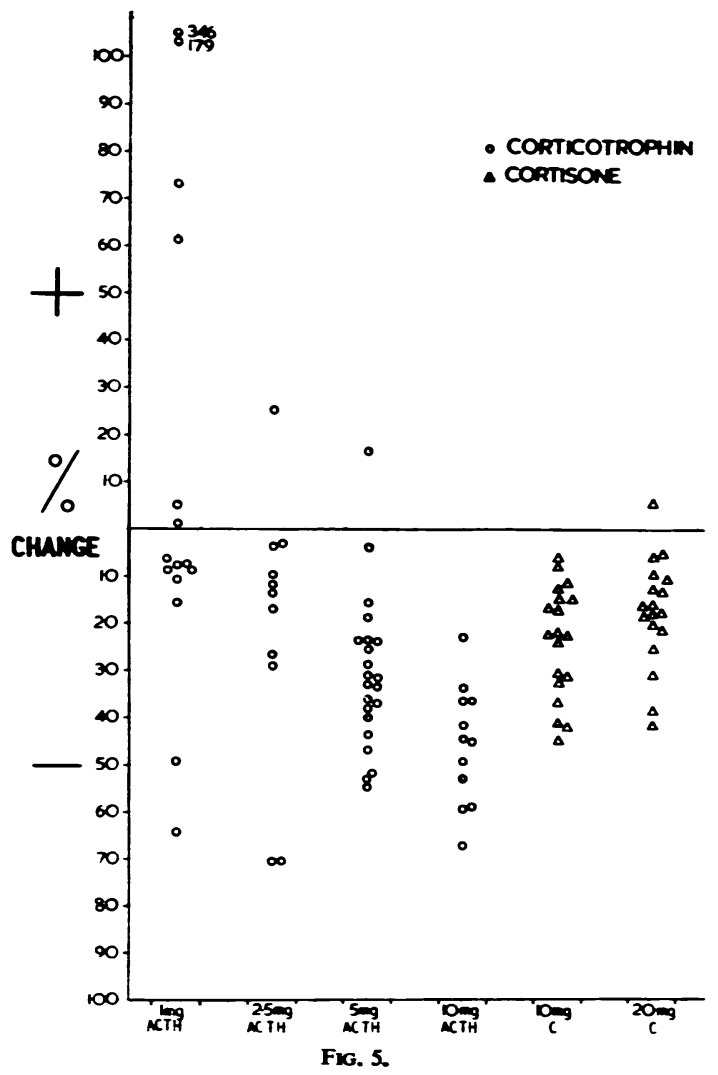

Fics. 5, 6 and 7.- Percentage change in cosinophil counts of normal infants on Days 1, 3 and 10 of life occurring four hours after varying doses of corticotrophin and cortisone.

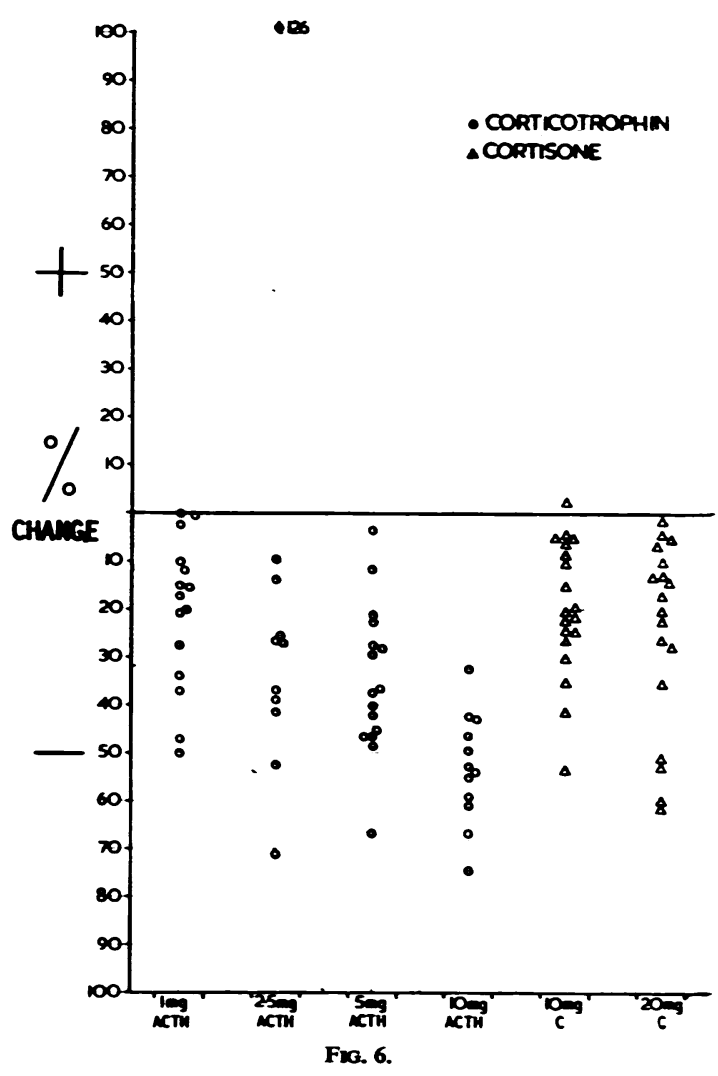

$\frac{\mathbb{2}}{\frac{1}{3}}$

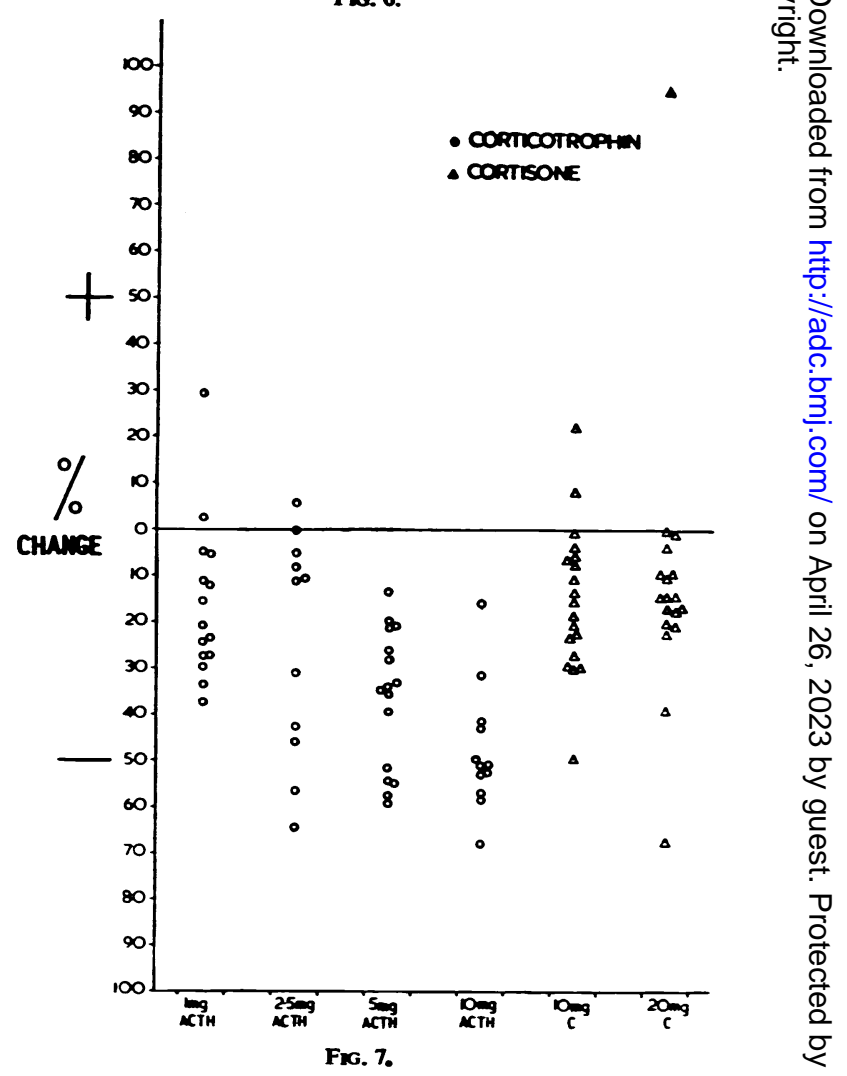


In $\mathbf{3 5}$ of the $\mathbf{4 6}$ infants the spontaneous change in four hours was either an increase or a decrease of less than $10 \%$. In only two of the 46 did the decrease exceed $20 \%$ (see Fig. 4).

It may also be seen from Figs. 1-3 that there was no correlation between the reaction of the baby to the taking of blood and the change in the eosinophil count over the next hour, nor were the changes related to the time of feeds.

\section{Part II}

Induced Change by Corticotrophin. The scatter of changes (expressed as percentages) in the eosinophil counts of the infants studied on the first, third and tenth days of life as the result of injecting $1,2.5$ or $5 \mathrm{mg}$. of corticotrophin is shown in Figs. 5-7. Two groups were given $10 \mathrm{mg}$. of corticotrophin, one receiving it on the first and third days and the other on days three and ten, and as the results on day three were almost identical in the two groups, the figures for that day from the first group were used in Figs. 5-7. Similarly, two groups were given $5 \mathrm{mg}$. corticotrophin in addition to the serial study and again there was little difference between them in the response on the third day.

EOSINOPHILIC Responses. The injection of $1 \mathrm{mg}$. of corticotrophin resulted in a substantial increase in the number of circulating eosinophils in four of the 15 cases the first day and a small increase occurred in a further two. One of the infants given $1 \mathrm{mg}$. on the third day also showed an increase in eosinophils.
The injection of $2.5 \mathrm{mg}$. provoked an increased eosinophil count in different cases on days one, three and ten, whereas only one small increment followed the injection of $5 \mathrm{mg}$. in a bigger series and none at all after the giving of $10 \mathrm{mg}$.

Eosinopenic Responses. The eosinopenic responses to the different doses of corticotrophin may be seen in Figs. 5-7. The scatter of response to each dose is considerable on each day, but from the graphs and from the frequency distribution table (Table 1), which takes into consideration larger groups of infants, it may be seen that in general the greater the dose of corticotrophin the greater the fall in the eosinophil count.

The mean percentage changes with the varying doses are recorded in Table 2, but when these means are re-calculated after the removal of the large positive values on day one it may be seen from Fig. 8 that the regression lines of the means indicate that a rough arithmetic relationship existed between the degree of change and the dose of corticotrophin injected.

The scatter of response to the varying doses overlaps widely, however, and by comparing Fig. 4 with Figs. 5-7 it may be seen that an appreciable number of the healthy infants studied had a spontaneous eosinolysis in four hours as great as that which in some followed the injection of corticotrophin. Certainly, with doses of $2.5 \mathrm{mg}$. or less, so many of the eosinopenic responses lay within $-20 \%$ that such a result would have no significance in individual cases. With $5 \mathrm{mg}$. a minority of

TABLE 1

FREQUENCY DISTRIBUTION OF EOSINOPHIL RESPONSES

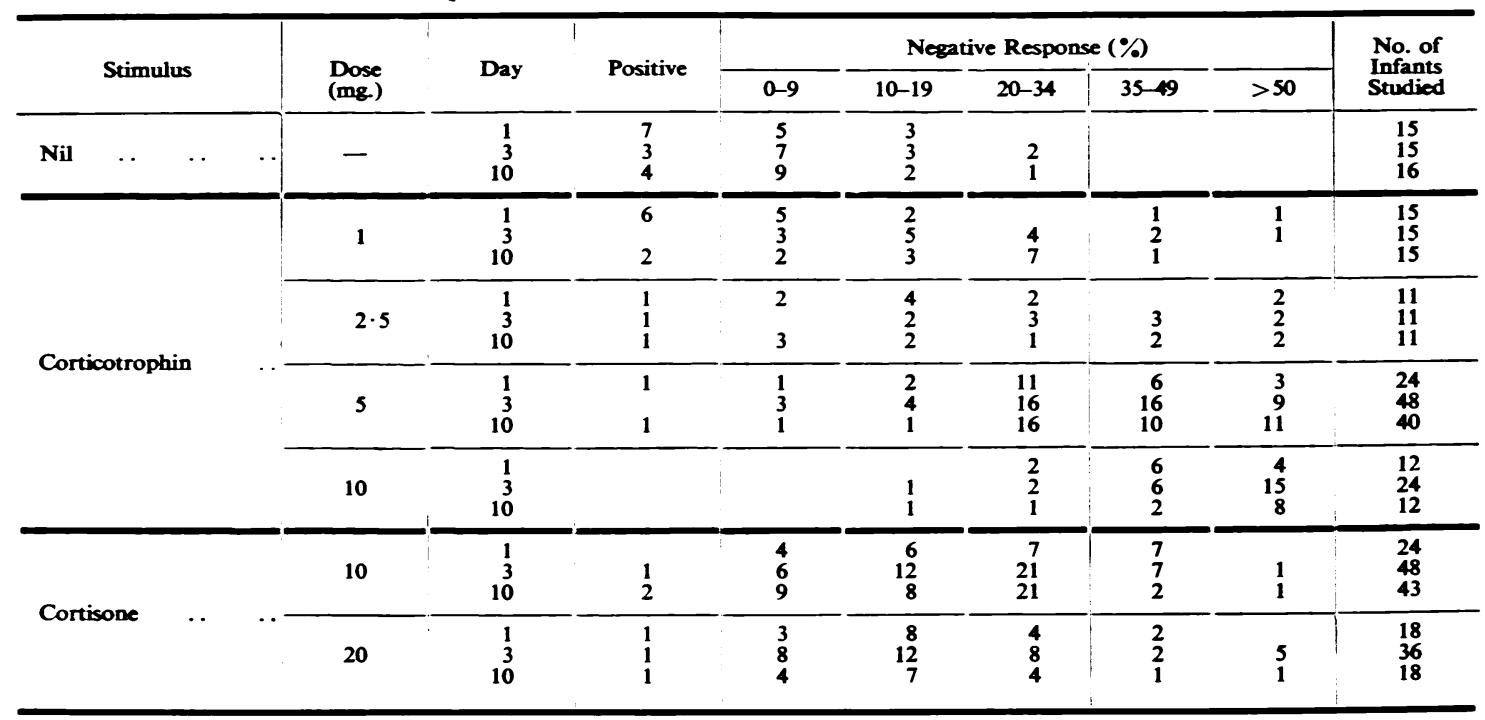


the responses was less than $-20 \%$, but only with $10 \mathrm{mg}$. was there almost universal response beyond that figure.

From the groups studied no significant evidence can be found to indicate that the response to corticotrophin was any more or less efficient on any of the three days.

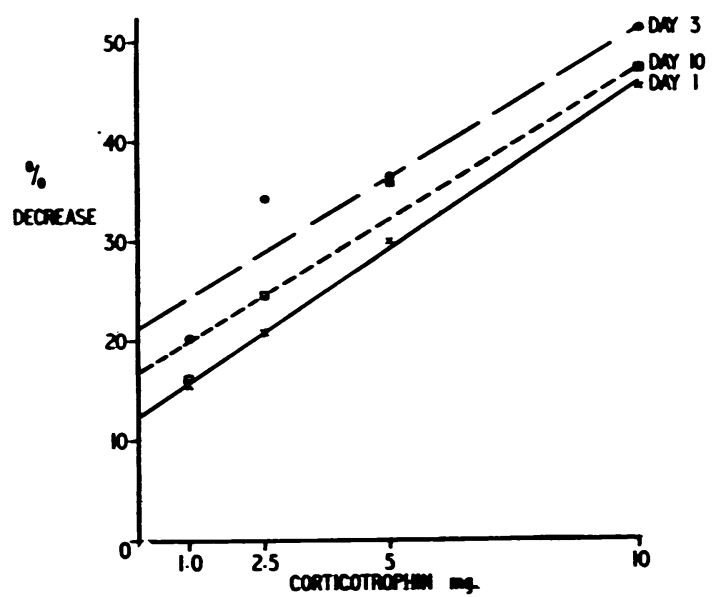

F1G. 8.-Average percentage decreases induced by corticotrophin in normal infants on Days 1,3 and 10.

Induced Changes by Cortisone. The results of injecting cortisone may be seen also in Figs. 5-7 and in Tables 1 and 2.

Only one significant eosinophilic response was obtained, and unlike those from corticotrophin it occurred on the tenth day.

As with corticotrophin there was considerable individual variation in eosinopenic response, and over the four-hour interval the response of the cortisone group as a whole was appreciably less than the response of the groups receiving half the dosage (by weight) of corticotrophin.

It may be seen also that the responses of the group receiving $20 \mathrm{mg}$. of cortisone were on the whole smaller than those of the group receiving $10 \mathrm{mg}$. The mean change on the third day with the greater dosage is in fact larger, but this is due to the influence on the mean of four decrements which fall well below the main scatter of responses.

\section{DISCUSSION AND INFERENCES}

Spontaneous variations sufficiently great to invalidate the Thorn test were described by Rud (1947) in adults, but he used an acetone stain which has been recognized as being capable of introducing error into eosinophil counting.

Swanson et al. (1952) undertook a careful study of the hourly spontaneous changes in adult absolute eosinophil values, and substantiated that diurnal variation did occur and that it was sufficiently great in the mornings to invalidate the test if carried out then. They concluded, however, that the eosinophil count was sufficiently stable in the afternoons to justify Thorn testing even although spontaneous decrements of up to $40 \%$ were found. It was postulated that the stress of wakening and the relaxation of sleep might exert an important effect on the number of circulating eosinophils and would explain why the spontaneous changes are commoner and greater in the morning. Tatai and Ogawa (1951) studied normal sedentary adults and found that the

TABLE 2

MEANS OF EOSINOPHIL CHANGES

\begin{tabular}{|c|c|c|c|c|c|c|c|}
\hline \multirow{2}{*}{\multicolumn{4}{|c|}{ Stimulus }} & \multicolumn{3}{|c|}{$\%$ Change in Four Hours } & \multirow{3}{*}{$\frac{\text { No. of Infants in Group }}{15}$} \\
\hline & & & & \multirow{2}{*}{$\begin{array}{l}\text { Day } 1 \\
-1 \cdot 5\end{array}$} & \multirow{2}{*}{$\begin{array}{l}\text { Day } 3 \\
-5 \cdot 7\end{array}$} & \multirow{2}{*}{$\begin{array}{l}\text { Day } 10 \\
-2 \cdot 5\end{array}$} & \\
\hline Nil (i.e. 'spon & ancous change') .. & $\cdots$ & $\ldots$ & & & & \\
\hline mz 1 & $\begin{array}{l}\text { Corticotrophin } \\
\text { Serial study }\end{array}$ & .. & $\ldots$ & $+32 \cdot 6$ & $-20 \cdot 6$ & $-16 \cdot 0$ & 15 \\
\hline mg. $2 \cdot 5$ & Serial study & . & $\cdots$ & $-20 \cdot 8$ & $-19 \cdot 7$ & $-24 \cdot 5$ & 11 \\
\hline \multirow{2}{*}{ mg 5} & Serial study & $\cdots$ & $\cdots$ & $-30 \cdot 0$ & $-34 \cdot 6$ & $-36 \cdot 5$ & 16 \\
\hline & \multicolumn{2}{|c|}{ Comparative groups } & $\cdots$ & $-30 \cdot 1$ & $\begin{array}{l}-34 \cdot 5 \\
-38 \cdot 5\end{array}$ & $-36 \cdot 0$ & $\begin{array}{l}24 \\
24\end{array}$ \\
\hline mg. 10 & \multicolumn{2}{|c|}{ Comparative groups } & $\ldots$ & $-45 \cdot 7$ & $\begin{array}{l}-53 \cdot 0 \\
-49 \cdot 9\end{array}$ & $-47 \cdot 6$ & $\begin{array}{l}12 \\
12\end{array}$ \\
\hline \multirow{2}{*}{ mg 10} & $\begin{array}{l}\text { Cortisone } \\
\text { Serial study }\end{array}$ & $\cdots$ & $\cdots$ & $-23 \cdot 6$ & $-19 \cdot 5$ & $-14 \cdot 9$ & 19 \\
\hline & \multicolumn{2}{|c|}{ Comparative groups } & $\ldots$ & $-24 \cdot 4$ & $\begin{array}{l}-21 \cdot 5 \\
-22 \cdot 7\end{array}$ & $-20 \cdot 9$ & $\begin{array}{l}24 \\
24\end{array}$ \\
\hline mg. 20 & \multicolumn{2}{|c|}{ Comparative groups } & $\cdots$ & $-17 \cdot 4$ & $\begin{array}{l}-24 \cdot 7 \\
-24 \cdot 5\end{array}$ & $-11 \cdot 7$ & $\begin{array}{l}18 \\
18\end{array}$ \\
\hline
\end{tabular}


absolute eosinophil count was maximum at night during sleep and minimum in the waking daylight hours.

Following the adjustments made by the infant to the start of extra-uterine life he is subjected to fewer stresses than the adult and his day is not divided into the same compartments of stress and relaxation. Much of his $\mathbf{2 4}$ hours is spent asleep protected from sudden changes in environmental temperature and with the sole disturbance of regular feeding. It was important, therefore, to determine whether the diurnal variation obtaining in adults occurred in newborn infants and whether feeding, with the associated processes of weighing and changing, or the painful stimulus occasioned by the taking of blood, were able to induce eosinophil decrements greater than $50 \%$.

Leucocyte counts at 15-minute intervals over three or four hours following bottle feeds were carried out by Mitchell (1915), and variations in the number of white cells were found. No particular attention was paid to eosinophils and there was no proof that the process of digestion was really responsible for the fluctuations. Washburn (1934) performed serial total white cell and differential counts on infants over the interval 9 a.m. to 5 p.m. and failed to find any pronounced variation in the total number of leucocytes. Those which did occur were produced largely by lymphocytic changes and were not related to ingestion, digestion, sleep, increased activity, or minor external disturbance. No absolute figures for eosinophils were given in the paper but the line of the hourly eosinophil values is depicted on the graphs of several infants, and, although they appear fairly stable, they are close to the base-line and the small fluctuations which do appear may amount to decrements of $30 \%$ or more.

In the present groups studied on the first, third and tenth days of life considerable stability of the eosinophil count over the same six hours in individual infants was found. Particular attention was paid to such spontaneous changes as might occur in the time interval zero to four hours for comparison with the eosinopenic responses to corticotrophin and cortisone. Usually at four hours the eosinophil count fell within the range $\pm 10 \%$ of the original value; in only two of the 46 individuals $(4 \%$ were the decrements in excess of $20 \%$ and in neither did they amount to $30 \%$.

Farquhar (1954), in a personal series and from a review of the literature, observed a trend toward higher eosinophil values on the third day than at any other time in the first 10 days with the exception of birth. The evidence suggesting under-activity of the adrenal cortex following upon the immediate response to the stress of birth was reviewed, but no correlation between day-to-day eosinophil and blood glucose change was found to substantiate the suggestion (Farquhar, 1954; Talbot, Sobel, McArthur and Crawford, 1952) that the explanation of the group trend toward rising eosinophil counts and falling blood glucose levels in the first few days might be that the production of 11-17 oxycorticosteroids was depressed at that time.

White and Sutton (1950) observed the eosinopenic responses of infants to adrenaline, accepted decrements of $35 \%$ or greater as implying normal adrenocortical response and regarded anything less than a $30 \%$ decrease as abnormal. Employing these criteria they concluded that the pituitary-adrenal response in healthy, full-term infants was normal, but no attention was paid to the age of the subject in days. Since the publication of their paper, however, the use of adrenaline in the test has fallen into disrepute in view of such inconsistent results as those demonstrated by Kark and Muehrcke (1952) among others.

The Thorn test employing corticotrophin has been shown to be of value in the assessment of the efficiency of the pituitary-adrenal mechanism in adults, provided it is remembered that 'it is subject to the limitations common to most laboratory tests' (de Mowbray and Bishop, 1953), and provided that the test is carried out in the afternoon to avoid the greater spontaneous variations occurring in the morning.

Klein and Hanson (1950) employed corticotrophin in the Thorn test on older children and seldom induced decrements much greater than $37 \%$. Employing this as their standard of normality they carried out the test on newborn infants. The infants of one group were tested once in the first three days and again in the second week with much better and more consistent falls in the latter. Two other groups were studied, one in the first week and the other in the second, with similar results. With $1 \mathrm{mg}$. or less of corticotrophin fewer 'positive' Thorn tests were obtained than when the dose was increased to 2-12 mg. and the $1 \mathrm{mg}$. dose was considered to be the more sensitive in demonstrating adrenocortical hypofunction. Venning (1950), however, employed much larger doses of corticotrophin in a small series and induced greater eosinophil responses in the second than in the first week.

In the present study doses of $2.5 \mathrm{mg}$. or less of corticotrophin were inadequate to provoke eosinopenic responses beyond the range of spontaneous change and appeared in some cases to induce an eosinophilia. The injection of $5 \mathrm{mg}$. was followed by an eosinopenia beyond the spontaneous range in 
the majority of cases, but only with $10 \mathrm{mg}$. was such a response consistently obtained.

In the groups studied, therefore, the dose of corticotrophin required to provoke eosinopenic responses greater than $20 \%$ in newborn infants was two-fifths as great as that required to induce a decrease of over $50 \%$ in the normal adult although the body weight of the infant was only about onetwentieth of the adult weight. Furthermore, even with this relatively high dose of corticotrophin decrements of $50 \%$ or greater occurred in about half the subjects only. The magnitude of the response was roughly proportionate to the dose given, but the dosages were so high relative to body weight that impotence of the particular batch of corticotrophin might be suspected had it not been excluded by comparison with others. These observations provide further suggestive evidence that relative inefficiency of the adrenocortical response to corticotrophin exists at this age.

White and Sutton (1950) found that adrenaline was relatively ineffective in provoking eosinopenia in premature infants, and, in order to exclude the possibility that this might be due not to functional under-activity of the adrenal but to abnormal resistance of the eosinophils to cortisone, they injected six infants with whole adrenal cortical extract and obtained an adequate eosinopenic response in all. They concluded that there was inability on the part of the premature infant to elaborate sufficient amounts of adrenal cortical hormone in response to corticotrophin. Klein and Hanson (1950) injected whole adrenal extract into 11 infants in the first two days of life with a view to excluding eosinophil resistance and obtained eosinopenic responses greater than $37 \%$ in eight of them in four hours.

In the present study cortisone was employed in preference to lipo-adrenal extract and proved to be less effective in inducing eosinopenia than half the dose by weight of corticotrophin. This at first appears to suggest eosinophil resistance. Evidence in favour of the suppression of adreno-cortical function by cortisone was published by McIntosh and Holmes (1951), and the more likely explanation of the poorer response to $20 \mathrm{mg}$. is that the injection of cortisone depressed endogenous adreno-cortical function and the resulting total of available cortisone was less than would have followed a smaller dose of corticotrophin.

The absolute eosinophil levels in Part I of this investigation were rather higher on the tenth than on the third day and so differed from the figures already published (Farquhar, 1954) and the figures from which the eosinopenic responses were calcu- lated in Part II of this study, both of which series were larger and showed higher absolute values on the third day. It had been considered possible that applying the Thorn test to newborn infants on the third day would show that the eosinopenic responses indicated a relative degree of adrenal cortical hypofunction compared with those induced on the first and tenth. The comparison of the group responses to corticotrophin on the three days, however, shows no significant difference between them, and if there is any doubtful trend at all it is toward rather better responses on the third day.

The Thorn test is of little value in the assessment of the health of the pituitary-adrenal axis in newborn infants because, unlike in adults where the great diurnal variation is the handicap, the response to relatively great doses of corticotrophin is so poor that it may be within the range of spontaneous variation.

In these conditions it is almost impossible to define what the normal eosinopenic response of a normal newborn infant to corticotrophin should be, but from the experience of this study it appears that the criteria might be a decrement of $30 \%$ or greater when $10 \mathrm{mg}$. are injected.

\section{SUMMARY AND CONCLUSIONS}

The literature referring to the Thorn test in adults and newborn infants is briefly reviewed.

The evaluation of the test in the newborn infant depends upon (a) the range of spontaneous eosinophil change, and $(b)$ the range of eosinopenic response to varying doses of corticotrophin.

Serial hourly studies of eosinophils in healthy infants showed considerable stability of absolute levels, and such fluctuations as did occur were unrelated to feeding and minor upsets.

Increasing doses of corticotrophin induced a proportionate increase in the mean eosinopenic response. There was, however, a considerable range of response to each dose on each day, and $10 \mathrm{mg}$. of corticotrophin were required to induce decrements greater than $30 \%$ consistently.

There was no significant difference in the nature of the response to the varying doses on the first, third and tenth days of life.

The Thorn test at this age is of little value because the poor eosinopenic responses to corticotrophin may fall within the range of spontaneous change. A normal response might be defined as a decrement of $30 \%$ or greater when a 10 -mg. dose is injected.

I wish to acknowledge my gratitude to Professor R. W. B. Ellis for his encouragement and advice, to 
Dr. E. C. Fahmy for permission to carry out these investigations in his obstetric unit, to Professor R. J. Kellar for laboratory space, to Professor D. M. Dunlop for supplies of corticotrophin and cortisone, and to Sister E. S. Somerville for invaluable help. Finally, I should like to pay tribute to Miss Pat Steven for her meticulous technical work in the laboratory.

Part of the work was carried out during the tenure of the George Guthrie Research Fellowship in Child Health.

\section{REFERENCES}

Farquhar, J. W. (1954). Archives of Disease in Childhood, 29, 519. Hilk, A. G., Forsham, P. H. and Finch, C. A. (1948). Blood, 3, 755 .

Kark, R. M. and Muehrcke, R. C. (1952). Lancet, 1, 1189.

Klein, R. and Hanson, J. (1950). Pediatrics, 6, 192.
McArthur, J. W., Smart, G. A., MacLachlan, E. A., Terry, M. L., Harting, D., Gautier, E., Godly, A., Swallow, K. A., Simeone, F. A., Zygmuntowice, A., Christo, E., Crepeaux, J., Point, W. W. and Benson, J. A. (1954). J. clin. Invest., 33, 420 . McIntosh, H. W. and Holmes, C. B. (1951). Lancet, 2, 1061. Mitchell, A. G. (1915). Amer. J. Dis. Child., 9, 358.

Mowbray, R. R. de and Bishop, P. M. F. (1953). Brit. med. J., $1,17$.

Rud, F.' (1947). Acta psychiat. Kbh., Suppl. 40, p. 1.

Selye, H. (1949). Textbook of Endacrimology, 2nd ed. Montreal.

Swanson, J. N., Bauer, W. and Ropes, M. (1952). Lancet, 1, 129.

Talbot, N. B., Sobel, E. H., McArthur, J. W. and Crawford, J. D. (1952). Functional Endocrinology from Birth Through Adol escence. Cambridge, Mass.

Tatai, K. and Ogawa, S. (1951). Jap. J. Physiol., 1, 328.

Thorn, G. W., Forsham, P. H., Prunty, F. T. G. and Hills, A. G. (1948). J. Amer. med. Ass., 137, 1005.

Venning, E. (1950). Proceedings of the First Clinical ACTH Conference, ed. Mote, J. R., p. 25. London.

Washburn, A. H. (1934). Amer. J. Dis. Child., 47, 993.

White, F. P. and Sutton, L. E. (1950). Pediatrics, 5, 876.

Zappert, J. (1893). Z. klin. Med., 23, 227. 